\title{
Ophthalmic Segment Aneurysms: Surgical Treatment and Outcomes
}

\author{
Rajneesh Kachhara ${ }^{1}$ Suresh Nair ${ }^{2}$ Pulak Nigam ${ }^{1}$ \\ 1 Department of Neurosurgery, Institute of Neurosciences, Medanta \\ Multi-speciality Hospital, Indore, Madhya Pradesh, India \\ ${ }^{2}$ Sree Chitra Tirunal Institute of Medical Sciences \& Technology, \\ Trivandrum, India \\ Address for correspondence Rajneesh Kachhara, MCh, Department \\ of Neurosurgery, Institute of Neurosciences, Medanta Multi-speciality \\ Hospital, Indore 452010, Madhya Pradesh, India \\ (e-mail: rkachhara@gmail.com).
}

J Neurosci Rural Pract 2021;12:635-641.

\begin{abstract}
Keywords

- aneurysms

- ophthalmic segment

- clinoid

- internal carotid

Background Surgical treatment of ophthalmic segment aneurysms (OSAs) remain challenging because of complex anatomy surrounding the aneurysm and entails extensive drilling of anterior clinoid process to define proximal neck of the aneurysm and carotid exposure in the neck for proximal control.

Materials and Methods Authors present a retrospective analysis of 36 aneurysms in 35 patients with OSAs operated surgically by first author. Surgical clipping was done for the aneurysms as primary modality of treatment along with wrapping and trapping as required. Results Commonest age group was 40 to 60 years with female preponderance of 3:1. Maximum (23) patients presented with subarachnoid hemorrhage (WFNS Gr 1), followed by asymptomatic patients (six). There were 18 small, 14 large, and four giant aneurysms, 15 dorsal wall, 17 ventral wall, three proximal posterior wall, and one blister aneurysm. Good outcome, as measured by Glasgow Outcome Score (GOS) was achieved in 29 patients.

Conclusion OSAs are technically demanding aneurysms, but with due diligence to surgical principles, good outcomes may be obtained.
\end{abstract}

\section{Introduction}

Ophthalmic segment aneurysms (OSA) arise from C6 segment of internal carotid artery (ICA). ${ }^{1}$ They are complex and surgical treatment is technically challenging as compared with other aneurysms of anterior circulation. Day has described them in detail, classifying them as dorsal wall and ventral wall aneurysm depending on their origin and projection from ICA. ${ }^{2}$ Over the years, different authors have variously classified these aneurysms based on the site of origin, the projection of the sac, and its relationship with branches arising from the ICA. Despite the technically challenging nature of the disease, there is a dearth of published literature dealing with technical nuances and outcomes of the aneurysm in Indian patients. The present article presents analysis of surgical techniques, nuances, and outcomes in 35 patients of OSAs treated by surgical clipping.

\section{Video 1}

Surgical video of clipping. Online content including video sequences viewable at: https://www.thiemeconnect.com/products/ejournals/html/10.1055/s-00411734002. published online September 30, 2021
DOI https://doi.org/ 10.1055/s-0041-1734002. ISSN 0976-3147.
(C) 2021. Association for Helping Neurosurgical Sick People. All rights reserved.

This is an open access article published by Thieme under the terms of the Creative Commons Attribution-NonDerivative-NonCommercial-License, permitting copying and reproduction so long as the original work is given appropriate credit. Contents may not be used for commercial purposes, or adapted, remixed, transformed or built upon. (https://creativecommons.org/ licenses/by-nc-nd/4.0/)

Thieme Medical and Scientific Publishers Pvt. Ltd., A-12, 2nd Floor, Sector 2, Noida-201301 UP, India 


\section{Materials and Methods}

\section{Inclusion}

This is a series of surgically treated patients of OSA by the first author consecutively at three centers, viz., Sree Chitra Tirunal Institute for Medical Sciences and Technology (SCTIMST), Trivandrum, Bombay Hospital, Indore and Medanta Super-specialty Hospital, Indore, Madhya Pradesh (MP), India over a period of 25 years. A total of 418 aneurysms were operated during this period, of which 36 aneurysms, in 35 patients, were defined as OSAs.

\section{Investigations}

All patients underwent computed tomography (CT) scan of brain with CT angiography and/or 4-vessel Digital Subtraction Angiography (DSA) as appropriate.

\section{Treatment}

All patients in this series underwent surgical treatment. Carotid artery was exposed in the neck for proximal control in all patients and was intermittently occluded for to facilitate dissection and clipping of aneurysm.

A pterional craniotomy was performed on the side of aneurysm. Adequate drilling of anterior clinoid process (ACP) is mandatory for better definition of proximal neck of aneurysm. This was done both intradurally and extradurally, the decision for the approach based on individual aneurysm morphology; ACP was drilled intradurally in majority of cases. However, of late, in selected ventral wall aneurysms the ACP was drilled extradurally.

Schematic diagrams of drilling extradurally and intradurally along with incision of falciform ligament to gain extra exposure of approximately $5 \mathrm{~mm}$ are shown in - Fig. 1 .

The definitive surgical procedure comprised of clipping of aneurysm. In case of aneurysm morphology not amenable to clipping, wrapping with muslin strands and piece of muscle and surgicel and trapping of aneurysm were other procedures employed. A short clip of clipping is appended. A short video of clipping is appended (-Video $\mathbf{1}$ ).

\section{Outcome Analysis}

Patients were followed up for a minimum period of 6 months. Glasgow Outcome Score (GOS) was used for outcome analy- sis. $^{3}$ Patients were grouped in four groups-good outcome, fair outcome, poor outcome, and death-based on GOS 1, 2, 3 to 4 , and 5 , respectively.

Patient data was collected and analyzed using IBM SPSS Statistics for Windows, (Version 23.0 Armonk, NY: IBM Corp).

\section{Results}

\section{Demography}

The commonest age group was 40 to 60 years ( 22 patients) with age ranging from 25 to 80 years. The youngest patient was 25 years and oldest patient was 80 years old. There were 26 females and 9 males with female to male ratio being 3:1.

\section{Symptomatology}

Twenty-seven patients presented with subarachnoid hemorrhage $(\mathrm{SAH})$ of which 23 patients were in WFNS grade 1 , three patients were in grade 2 to 3 , and one patient was in grade 4 . The duration of SAH prior to definitive treatment ranged from 5 days to 3 weeks. One of the patients had acute hydrocephalus following $\mathrm{SAH}$.

One patient presented with visual loss and another patient had thromboembolic episodes at presentation. Six patients had presented with other associated pathologies such as meningioma, craniopharyngioma, epidermoid or other aneurysms and were found during evaluation to have an incidental OSA.

\section{Aneurysm Morphology}

The aneurysms were classified according to size and projections. There were 18 small aneurysms, 14 large and four giant aneurysms. Fifteen aneurysms arose from dorsal wall and projected dorsally or dorsomedially (in relation to ophthalmic artery), 17 aneurysms arose from ventral wall and projected ventrally or ventromedially (in relation to superior hypophyseal artery), three aneurysms arose from proximal posterior wall and projected posterolaterally and one of the aneurysms was blister aneurysm that arose from distal dorsal wall and projected dorsomedially. Some aneurysms morphologies are shown in - Fig. 2.

\section{Associated Lesions}

There were associated lesions with OSA in some patients: superior cerebellar artery aneurysm (1), clinoidal meningioma
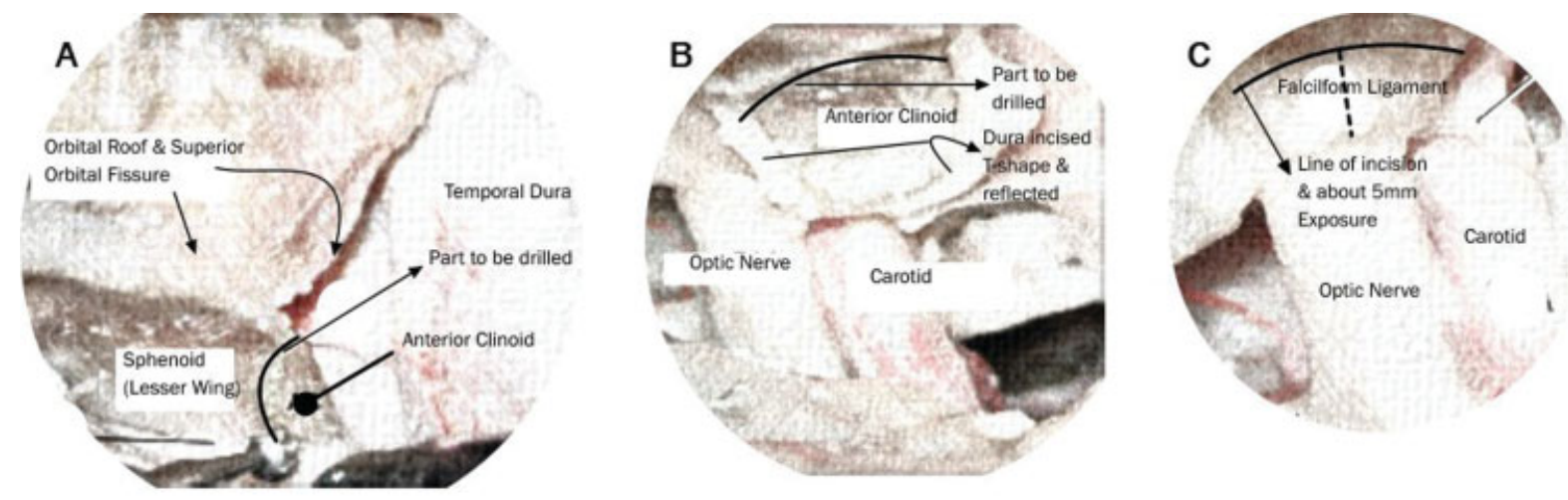

Fig. 1 (A-C) Schematic drawings of extradural and intradural clinoid drilling. 
(1), anterior communicating artery aneurysm (1), craniopharyngioma (1), epidermoid (1).

One of the patients with incidentally detected OSA had multiple associated lesions-an anterior communicating aneurysm which had ruptured, an MCA bifurcation aneurysm and a pituitary adenoma. All were treated in same operation.

\section{Surgical Procedure}

The aneurysm was clipped in 31 patients, wrapping with muslin with further buttressing with muscle was done in three patients and one patient with adequate cross-circulation underwent trapping of aneurysm.

Intraoperative rupture occurred in seven patients, which was controlled with compression of carotid in neck and applying permanent clips after defining the site of aneurysm rupture.

\section{Outcome}

Outcome was analyzed using GOS after following up patients for a minimum of 6 months. Good outcome was achieved in 29 patients (82.8\%), four patients were moderately disabled but independent (fair outcome, 11.4\%) and two patients died (5.7\%). [ - Table 1]

\section{Visual Outcome}

Only one patient had presented with visual symptoms. It was a giant left OSA, which was compressing left optic nerve that resulted in visual deterioration. The patient showed improvement in vision following surgical clipping and decompression of aneurysm sac. None of the other patients had any visual deterioration following surgical manipulation while clipping of aneurysms.

\section{Outcomes in Patients with Wrapping/Trapping}

Of the three patients who underwent wrapping all had good surgical outcome. Repeat angiogram could not be done for these patients for logistical reasons but they remained stable clinically and neurologically during their follow- up. One patient who underwent trapping has been on follow-up for more than 10 years and continues to remain asymptomatic.

\section{Outcomes over the Years}

In a course of any series spanning 25 years, the outcomes of initial years when surgical paraphernalia was limited, and technique and skills were evolving are bound to be different from the time when our techniques have become nuanced and surgical armamentarium has become state-of-art. Similarly, over the years our access to technology and our technical skills have improved and reflected in surgical results.

\section{Discussion}

Treating paraclinoid aneurysms is a challenge even for experienced neurosurgeons. These aneurysms have, in past been termed unclippable or been associated with suboptimal outcomes. ${ }^{4,5}$ Increasingly, these aneurysms are being treated endovascularly. However, with advancement and refinement of surgical techniques, the results in present era are good and excel that of endovascular treatment insofar as total neck obliteration and recanalization is concerned. ${ }^{5-8}$

\section{Incidence and Symptomatology}

OSAs occur in less than 5 to $9 \%$ of anterior circulation aneurysms. They have been reported to be commoner in females and are associated with other aneurysms in approximately $20 \%$ of cases. ${ }^{5}$ In our series, the incidence of OSA was $8.75 \%$ of all anterior circulation aneurysms, was nearly three times commoner on females and was associated with other aneurysms in nearly $14 \%$ of cases.

These aneurysms can grow to large size and abut against optic nerve and frequently it is the visual symptoms that prompt medical attention rather than SAH, although SAH still remains the commonest presentation. ${ }^{5,9,10}$ In our series, the most common presentation was that of SAH

Table 1 Comparison of surgical series

\begin{tabular}{|l|l|l|l|l|l|l|}
\hline Comparison of surgical series & $\begin{array}{l}\text { Aneurysms/ } \\
\text { Patients }\end{array}$ & $\begin{array}{l}\text { Clipping } \\
(\%)\end{array}$ & $\begin{array}{l}\text { Good outcome } \\
(\%)\end{array}$ & $\begin{array}{l}\text { Fair outcome } \\
(\%)\end{array}$ & $\begin{array}{l}\text { Poor outcome } \\
(\%)\end{array}$ & $\begin{array}{l}\text { Mortality } \\
(\%)\end{array}$ \\
\hline Author (year) & $14 / 14$ & 50 & 40 & - & - & 60 \\
\hline Drake et al (1968) & $54 / 54$ & 96 & 87 & - & 7 & 6 \\
\hline Day (1990) & $89 / 89$ & & 87 & 9 & 3 & 1 \\
\hline Batjer et al (1994) & $16 / 16$ & 94 & 88 & 6 & - & 6 \\
\hline Arnautovic et al (1998) & $29 / 29$ & 96 & 89 & - & 7 & 3.5 \\
\hline Kattner et al (1998) & $35 / 28$ & 88 & 89 & 7 & - & 3.5 \\
\hline De jesús et al (1999) & $108 / 104$ & 81 & 83 & 7 & 5.7 & 3.8 \\
\hline Raco et al (2008) & $40 / 38$ & 76.3 & 76.3 & - & 18.4 & 5.3 \\
\hline Liu et al (2008) & $137 / 91$ & 94 & 88 & 7.6 & - & 4 \\
\hline Nathal and Castillo (2008) & $34 / 33$ & 85 & 79.4 & 11.8 & - & 5.9 \\
\hline Present series (2017) & & & & \\
\hline
\end{tabular}


(73.6\%), while visual symptoms were present in merely 3\% of the cases. Larger cohorts are required to infer whether Indian population is more prone to rupture of these aneurysms.

\section{Anatomical Considerations}

The ICA has been variously classified by Fisher, Gibo, Lasjaunias and Berenstein, and Bouthillier et al, with the latter being the commonest. ${ }^{111-13}$ Ophthalmic segment corresponds to C6 segment of Bouthillier's classification.

Given the crowded paraclinoidal space and presence of important neurovascular structures, minimal manipulation of these structures and adequate proximal control form the cornerstone of good postoperative outcome. ${ }^{6-8,14,15}$

\section{Classification}

These aneurysms have been variously classified based on the site of origin of the neck, the projection of the dome, and its relationship with branches arising from the ICA. ${ }^{2,5,8,14-18} \mathrm{~A}$ simpler, surgically relevant method is to classify the aneurysms according to their origin in relation to the circumference of ICA and branching artery and the projection of the dome.

The aneurysms may thus be classified as ${ }^{5}$ :

1. Dorsal aneurysms-These include aneurysms arising from distal dorsal wall (dorsal wall aneurysms), aneurysms of proximal wall, and blister aneurysms of dorsal wall. Dorsal wall aneurysms are situated at dorsal wall of ICA, in relation to ophthalmic artery and tend to project dorsally or dorsomedially. Proximal wall aneurysms tend to project upward and are more prone to cause visual symptoms.
In our series, $53 \%$ of the aneurysms originated from dorsal wall $(41.2 \%$ dorsal wall, $8.8 \%$ proximal wall, and $2.9 \%$ blister).

2. Ventral aneurysms-These aneurysms are located on the ventral or ventromedial wall, diagonally opposite to ophthalmic artery and in close relation with superior hypophyseal artery.

In our series, $47 \%$ of aneurysms were ventral aneurysms. Day has classified these aneurysms into ophthalmic artery aneurysms-that arise just distal to origin of ophthalmic artery and project dorsally or dorsomedially-and superior hypophyseal aneurysms-that arise more distally and incorporate perforators to hypophysis. These are further subdivided into paraclinoid variant, which projects inferiorly or inferomedially beneath ACP, and suprasellar variant, which projects medially or superomedially above diaphragma sella. ${ }^{2}$

\section{Surgical Nuances}

The important surgical nuances include proximal carotid control, frontotemporal craniotomy with drilling of lesser wing of sphenoid, wide opening of Sylvian fissure, and microsurgical dissection of cisterns and bony drilling to remove $A C P$, which exposes approximately 6 to $7 \mathrm{~mm}$ of proximal carotid artery.

\section{Proximal Carotid Control}

The proximal carotid control may be achieved by one of the four approaches, proximal control in neck, exposure of petrous ICA in middle fossa, intracranial control of ICA after opening of distal dural ring, or endovascular ICA occlusion. $6,14,19-21$
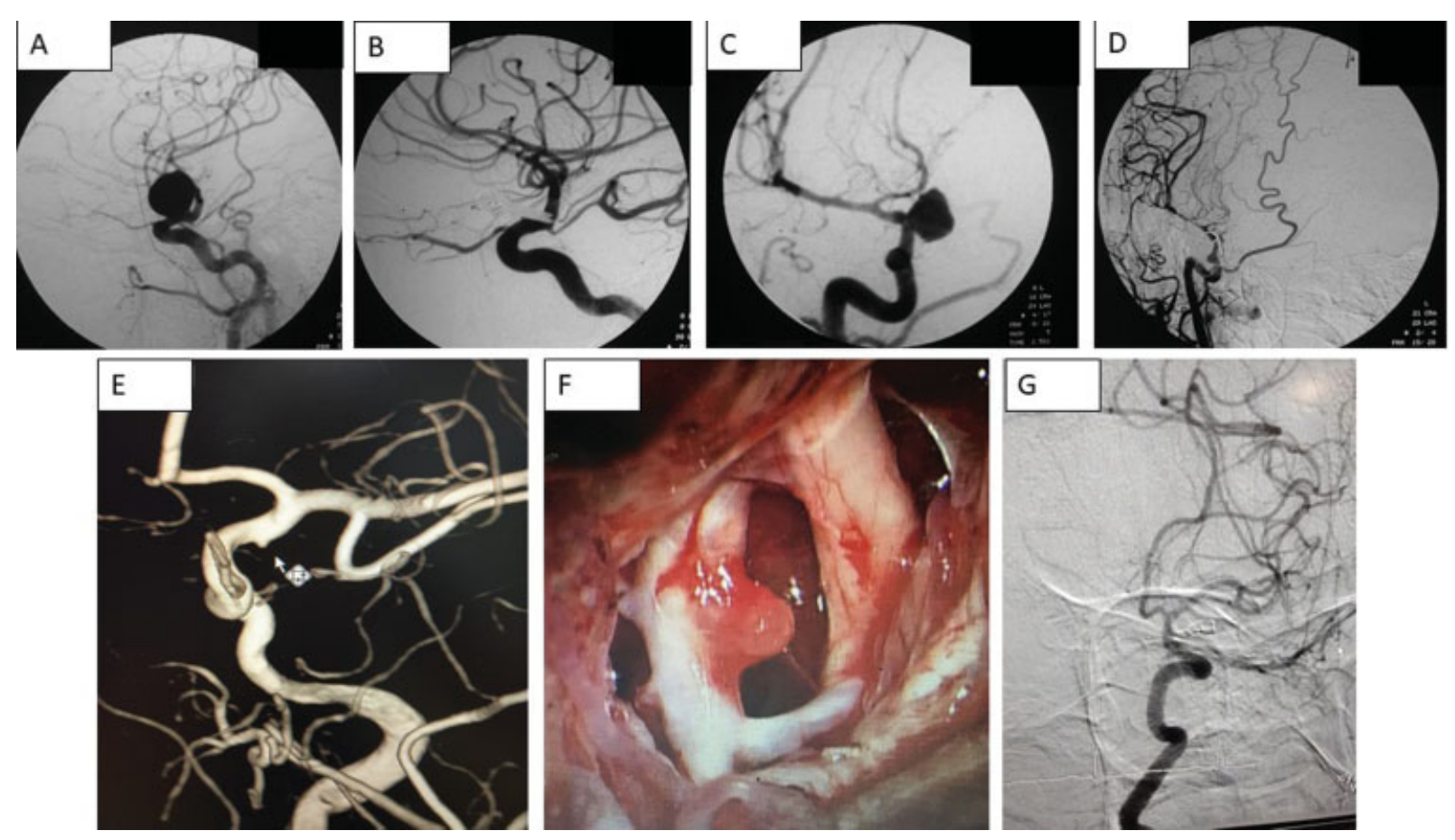

Fig. 2 Preoperative and postoperative angiograms of various ophthalmic segment aneurysms. (A, B) Dorsal wall, (C, D) Ventral wall, (E, G) Blister aneurysm, and ( $F$ ) shows intraoperative picture of a blister aneurysm. 
The proximal carotid control in neck is not only the simplest and safest method, but it is also achieved before the start of craniotomy and secures ICA early which is especially important in case of premature rupture. ${ }^{5,14}$ We achieved proximal carotid control in neck in all our cases.

\section{Drilling of ACP}

Drilling of ACP along with proximate bone structures like optic roof and optic strut form the cornerstone of adequate exposure of aneurysm and its subsequent clipping. ACP must be drilled in all cases notwithstanding the size of the aneurysm. ${ }^{5,22}$ ACP can be drilled extradurally or intradurally. ${ }^{6,23}$ In cases of dorsal wall aneurysms, extradural drilling alone may be riskier, and it is judicious to combine it with intradural technique. ${ }^{5}$ Several factors are pertinent in this regard. Dorsal wall aneurysms carry a risk of premature rupture due to transmitted vibrations of drilling. These aneurysms may occasionally erode ACP and planum sphenoidale and this may itself lead to premature rupture in case wholly extradural drilling is attempted; in addition, acute SAH associated with these aneurysms may cause severe brain swelling that may make completion of extradural drilling difficult-and thus require final phase of drilling to be completed intradurally.

Various authors have suggested various techniques for effective bone removal including use of diamond drills, copious irrigation, and frequent pauses to dissipate heat, use of bone ultrasonic aspirators, drilling the cancellous core, and cavitating ACP before its detachment. 5,22,24,25

Samson has opined on the amount of bone resection needed for adequate exposure of these aneurysms. They recommend (1) unroofing of the optic canal, aggressive resection of the optic strut for ophthalmic artery aneurysm; minimal removal of the ACP may suffice in these cases; (2) extensive ACP drilling for superior hypophyseal aneurysms though optic roof may not need to be drilled, and (3) aggressive ACP drilling but leaving optic strut and roof intact for ICA-paraclinoid aneurysms. ${ }^{22}$ We de-roof optic canal and resect falciform ligament in all cases mandatorily as it enables optic nerve manipulation, if needed, without the risk of injury.

We have performed intradural drilling for majority of our initial cases. Of late, we increasingly attempt to perform extradural drilling for ventral wall aneurysms. A few caveats remain to this. For ventral wall aneurysms, it is safer to drill the last part of tip of large ACP intradurally. In cases where the brain is tense, a complete extradural drilling and removal is not attempted. Instead, after substantial extradural removal, the rest of drilling is done intradurally after release of CSF, which allows brain to become lax and affords clearer view of anatomy of the surgical field.

\section{Preference and Selection of Cases for Extradural Drilling}

A small ventrally projecting aneurysm from ophthalmic segment, is the aneurysm where we can drill ACP extradurally with safety. It must be borne in mind that while extradural drilling is less likely to transmit vibrations from drilling to the aneurysm, intradural drilling is under vision and considerably safer.

\section{Endovascular Techniques: Pertinent Considerations}

Ever since approval of Guglielmi coils by FDA in 1995, endovascular techniques have been increasingly more employed for treatment of these aneurysms. These techniques include coiling, stenting, and flow diversion. ${ }^{26}$ The occlusion of aneurysm using these techniques is measured in accordance with Raymond scale. ${ }^{27}$ Complete occlusion (Raymond class 1 ) is achieved in 40 to $72 \%$ with coiling, with higher rates in smaller aneurysms and stent-assisted coiling and in 69 to $95 \%$ with flow diversion. ${ }^{28-33}$ With coiling, 5 to $19 \%$ of aneurysms may only be partially occluded (Raymond class 3$)^{28,29,31,32}$

Overall rates of permanent mortality and morbidity with coiling is up to $2 \%$ and $8 \%$, respectively, while 4 to $7 \%$ of patients experience thromboembolic complications. Around 14 to $17 \%$ of aneurysms have a recurrence when treated with coiling. ${ }^{28,30-33}$ On the other hand, flow diverters have mortality and morbidity of up to $19 \%$ associated with them. ${ }^{34-39}$ In addition, use of stent during coiling or flow diverters is associated with necessity of long-term antiplatelet therapy.

Cost of coiling in similar patients with similar uncomplicated hospital course is about twice that of clipping at our present center. Necessity of stent or use of flow diverters inflates this anywhere between four and five times the costs of clipping.

We firmly hold the opinion that while endovascular techniques are gaining ascendancy, clipping forms a cornerstone of treatment of these aneurysms. Cost of endovascular procedures and devices form an important consideration in resource limited third word tertiary care centers. Long-term antiplatelet requirement and monitoring for thromboembolic episodes (and their treatment, should they occur) only serve to contribute further to the cost. In addition, regular follow-up and checking of DSA at regular intervals to look for re-canalization are mandatory for endovascular treatment.

Presence of large hematoma, severe mass effect, large aneurysms causing compression of optic nerve, and much better and direct control in case of intraprocedural rupture are a few of clinical scenarios where clipping has definite edge over endovascular techniques.

\section{Blister Aneurysms}

Blister aneurysms form a distinct subset of their own with unique risks and complications. Surgical strategy remains the same as in any other aneurysm so far as proximal control in neck and drilling of ACP to delineate aneurysm is concerned. Dissection remains gentle and carotid needs to be temporarily occluded for dissection and permanent clipping. While clipping some part of normal wall of carotid has to be included in the clip for secure exclusion of aneurysm from circulation. A prophylactic STA-MCA bypass should be given due consideration, in case ICA needs to be trapped, should the aneurysm rupture intraoperatively. Endovascular means like flow diverters are also being used with success. 


\section{Outcomes}

The gradual and incremental refinement of surgical technique and advancement of surgical paraphernalia has led to vast improvement in outcomes in these aneurysms, from the early days when Drake et al, reported 50\% clipping rate and 60\% mortality to present era with clipping rates of 80 to $96 \%$, good outcome in 76 to $89 \%$ patients, and mortality as low as 3 to $6 \%$. 2,4,5,9,14,40-43

In our series, the results were comparable to concurrently reported Figures (85\% clipping, good outcome in 79\% patients, and mortality of $5.9 \%$ ) despite our primary presentation being aneurysmal rupture and SAH in comparison to western literature where visual deterioration is a common presentation as well.

\section{Conclusion}

OSAs are technically demanding aneurysms, but with due diligence to surgical principles, the good outcomes may be obtained. This includes drilling of ACP, wide dissection of neck, and achieving early proximal control.

\section{Ethical Approval}

All procedures performed in the studies involving human participants were in accordance with the ethical standards of the institutional and/or national research committee (name of institute/committee) and with the 1964 Helsinki declaration and its later amendments or comparable ethical standards. Informed consent was obtained from all individual participants included in the study.

\section{Funding}

None.

\section{Conflict of Interest}

None declared.

\section{References}

1 Bouthillier A, van Loveren HR, Keller JT. Segments of the internal carotid artery: a new classification. Neurosurgery 1996;38(03): 425-432, discussion 432-433

2 Day AL. Aneurysms of the ophthalmic segment. A clinical and anatomical analysis. J Neurosurg 1990;72(05):677-691

3 Jennett B, Bond $M$. Assessment of outcome after severe brain damage. Lancet 1975;1(7905):480-484

4 Drake CG, Vanderlinden RG, Amacher AL. Carotid-ophthalmic aneurysms. J Neurosurg 1968;29(01):24-31

5 Nathal E, Castillo G. Surgical treatment of paraclinoid aneurysms. In: Quiñones-Hinojosa A, ed. Schmidek and Sweet's Operative Neurosurgical Techniques: Indications, Methods, and Results. Philadelphia, PA: Saunders; 2012:855-871

6 Khan N, Yoshimura S, Roth P, et al. Conventional microsurgical treatment of paraclinoid aneurysms: state of the art with the use of the selective extradural anterior clinoidectomy SEAC. Acta Neurochir Suppl (Wien) 2005;94:23-29

$7 \mathrm{Xu}$ BN, Sun ZH, Jiang JL, et al. Surgical management of large and giant intracavernous and paraclinoid aneurysms. Chin Med J (Engl) 2008;121(12):1061-1064
8 Yasargil MG, Gasser JC, Hodosh RM, Rankin TV. Carotid-ophthalmic aneurysms: direct microsurgical approach. Surg Neurol 1977;8(03):155-165

9 Kattner KA, Bailes J, Fukushima T. Direct surgical management of large bulbous and giant aneurysms involving the paraclinoid segment of the internal carotid artery: report of 29 cases. Surg Neurol 1998;49(05):471-480

10 Nonaka T, Haraguchi K, Baba T, Koyanagi I, Houkin K. Clinical manifestations and surgical results for paraclinoid cerebral aneurysms presenting with visual symptoms. Surg Neurol 2007;67(06):612-619, discussion 619

11 Fischer E. Die lageabweichungen der vorderen hirnarterie im gefassbild. . Neurochir 1938;3:300-313

12 Gibo H, Lenkey C, Rhoton AL Jr. Microsurgical anatomy of the supraclinoid portion of the internal carotid artery. J Neurosurg 1981;55(04):560-574

13 Lasjaunias P, Berenstein A. Arterial Anatomy: Introduction. Surgical Neuroangiography Springer; 1987:1-32

14 Batjer HH, Kopitnik TA, Giller CA, Samson DS. Surgery for paraclinoidal carotid artery aneurysms. J Neurosurg 1994;80(04): 650-658

15 Dolenc VV. A combined epi- and subdural direct approach to carotid-ophthalmic artery aneurysms. J Neurosurg 1985;62(05): 667-672

16 Kinouchi H, Mizoi K, Nagamine Y, et al. Anterior paraclinoid aneurysms. J Neurosurg 2002;96(06):1000-1005

17 Kobayashi S, Kyoshima K, Gibo H, Hegde SA, Takemae T, Sugita K. Carotid cave aneurysms of the internal carotid artery. J Neurosurg 1989;70(02):216-221

18 Nakagawa F, Kobayashi S, Takemae T, Sugita K. Aneurysms protruding from the dorsal wall of the internal carotid artery. J Neurosurg 1986;65(03):303-308

19 Bulsara KR, Patel T, Fukushima T. Cerebral bypass surgery for skull base lesions: technical notes incorporating lessons learned over two decades. Neurosurg Focus 2008;24(02):E11

20 Mastronardi L, Sameshima T, Ducati A, De Waele LF, Ferrante L, Fukushima T. Extradural middle fossa approach. Proposal of a learning method: the "rule of two fans." Technical note. Skull Base 2006;16(03):181-184

21 Thorell W, Rasmussen P, Perl J, Masaryk T, Mayberg M. Balloonassisted microvascular clipping of paraclinoid aneurysms. Technical note. J Neurosurg 2004;100(04):713-716

22 Samson DS, ed. Intracranial Aneurysm Surgery: Basic Principles and Techniques. NY: Thieme; 2012

23 Noguchi A, Balasingam V, Shiokawa Y, McMenomey SO, Delashaw JB Jr. Extradural anterior clinoidectomy. Technical note. J Neurosurg 2005;102(05):945-950

24 Hadeishi H, Suzuki A, Yasui N, Satou Y. Anterior clinoidectomy and opening of the internal auditory canal using an ultrasonic bone curette. Neurosurgery 2003;52(04):867-870, discussion 870-871

25 Lawton MT. Seven Aneurysms: Tenets und Techniques for Clipping. New York, NY: Thieme; 2011

26 Brown B, Hanel RA. Endovascular management of cavernous and paraclinoid aneurysms. Neurosurg Clin N Am 2014;25(03): 415-424

27 Raymond J, Guilbert F, Weill A, et al. Long-term angiographic recurrences after selective endovascular treatment of aneurysms with detachable coils. Stroke 2003;34(06):1398-1403

28 D’Urso PI, Karadeli HH, Kallmes DF, Cloft HJ, Lanzino G. Coiling for paraclinoid aneurysms: time to make way for flow diverters? AJNR Am J Neuroradiol 2012;33(08):1470-1474

29 Fargen KM, Hoh BL, Welch BG, et al. Long-term results of enterprise stent-assisted coiling of cerebral aneurysms. Neurosurgery 2012;71(02):239-244, discussion 244

30 Gurian JH, Viñuela F, Guglielmi G, Gobin YP, Duckwiler GR. Endovascular embolization of superior hypophyseal artery aneurysms. Neurosurgery 1996;39(06):1150-1154, discussion 1154-1156 
31 Park HK, Horowitz M, Jungreis C, et al. Endovascular treatment of paraclinoid aneurysms: experience with 73 patients. Neurosurgery 2003;53(01):14-23, discussion 24

32 Roy D, Raymond J, Bouthillier A, Bojanowski MW, Moumdjian R, L'Espérance G. Endovascular treatment of ophthalmic segment aneurysms with Guglielmi detachable coils. AJNR Am J Neuroradiol 1997;18(07):1207-1215

33 Thornton J, Aletich VA, Debrun GM, et al. Endovascular treatment of paraclinoid aneurysms. Surg Neurol 2000;54(04):288-299

34 Becske T, Kallmes DF, Saatci I, et al. Pipeline for uncoilable or failed aneurysms: results from a multicenter clinical trial. Radiology 2013;267(03):858-868

35 Byrne JV, Beltechi R, Yarnold JA, Birks J, Kamran M. Early experience in the treatment of intra-cranial aneurysms by endovascular flow diversion: a multicentre prospective study. PLoS One 2010;5 (09):e12492

36 Lubicz B, Collignon L, Raphaeli G, De Witte O. Pipeline flowdiverter stent for endovascular treatment of intracranial aneurysms: preliminary experience in 20 patients with 27 aneurysms. World Neurosurg 2011;76(1-2):114-119

37 Lylyk P, Miranda C, Ceratto R, et al. Curative endovascular reconstruction of cerebral aneurysms with the pipeline embolization device: the Buenos Aires experience. Neurosurgery 2009;64(04): 632-642, discussion 642-643, quiz N6

38 Nelson PK, Lylyk P, Szikora I, Wetzel SG, Wanke I, Fiorella D. The pipeline embolization device for the intracranial treatment of aneurysms trial. AJNR Am J Neuroradiol 2011;32(01):34-40

39 Szikora I, Berentei Z, Kulcsar Z, et al. Treatment of intracranial aneurysms by functional reconstruction of the parent artery: the Budapest experience with the pipeline embolization device. AJNR Am J Neuroradiol 2010;31(06):1139-1147

40 Arnautović KI, Al-Mefty O, Angtuaco E. A combined microsurgical skull-base and endovascular approach to giant and large paraclinoid aneurysms. Surg Neurol 1998;50(06):504-518, discussion 518-520

41 De Jesús O, Sekhar LN, Riedel CJ. Clinoid and paraclinoid aneurysms: surgical anatomy, operative techniques, and outcome. Surg Neurol 1999;51(05):477-487, discussion 487-488

42 Liu Y, You C, He M, Cai B-W. Microneurosurgical management of the clinoid and paraclinoid aneurysms. Neurol Res 2008;30(06): 552-556

43 Raco A, Frati A, Santoro A, et al. Long-term surgical results with aneurysms involving the ophthalmic segment of the carotid artery. J Neurosurg 2008;108(06):1200-1210 